\title{
INTRODUCTION: Epistemology and Practice of Interdisciplinarity ${ }^{1}$
}

\author{
Prof. Abhi Subedi (Nepal)
}

Pokhara is the right space to talk about interdisciplinarity because it is a trope of unusually powerful order that incorporates all the various strands of studies opened up by this mode of study today. We must use the latest model of interdisciplinary studies to understand the Pokhara trope that I would like to mention here by way of introducing the subject. Theo van Leeuwen of Cardiff University shows three models of interdisciplinarity-the centrist, pluralist and integrationist. He says, we do not choose out of them, because they should be seen as different forms of development. However, he sees 'the the third and most recent, "integrationist" model as the way forward for interdisciplinary research... ?2 But each model 'sees itself as the centre of the universe of knowledge'. The pluralist model would work fine but it too sees one model at the centre and other models making up the cluster around it 'as equal partners'. The question that needs to be answered in an interdisciplinary seminar such as this or any other, for that matter, is--are the different disciplines gathered here to report the problems and project their own sense of loss and achievement, or have they come to find an 'integrationist' model to find a common solution to common problems? I would like to address this question by saying that the papers, the gist of which I had an opportunity to read, address an integrationist problem. I would like to elaborate this by going back to the Pokhara valley metaphor as the locus of all strands of phenomenal happenings in geological times and in our own times, here and now.

Pokhara has seen in the catastrophic avatar of Seti some time ago, a converging moment of global and local phenomena. Most spectacular interpretations of the global warming, rejection of such theory and search for other interpretations opened up new debates about the Seti deluge that Nepal had never seriously taken up before. One mode of interdisciplinary study is the evocation of globalism. I personally feel, any time we speak about interdisciplinarity either in science, or in literature, we speak in terms of global anxiety and thrill. I want to recall two tremendous events that happened in arts in the years 2009 and 2012 under the rubric Kathmandu International Arts Festival (KIAF) in Kathmandu. It was organized by Siddhartha Arts Foundation. The theme of the last festival was 'earth, body, mind'. This festival brought 71 international and 21 national artists together. The global concern about climate change and its effect in the environment was addressed not by scientists but by artists. But the artists used the same subjects that scientists, geographers, environmentalists, 


\section{Crossing the Border: International Journal of Interdisciplinary Studies}

managers, chemists, physicists, lawyers and meteorologists have been addressing. The Festival brought poets and philosophers, gender and ethnic study persons together. I also moderated some very memorable colloquiums during the monthlong festival held in the month of winter. But what struck me as the integrationist model of the interdisciplinarity was the modus operandi chosen by artists from all over the world. The best and the most effective genre of art is installation art-which is visual, physical and tactile manifestation of arts. It gained great currency in the industrialized countries where to cope with the magnanimity of the ecological disaster artists used the same objects that spelt disaster. The negative became the motif, but artists turned that into a visible pattern that became a power. The artists used rocks, soil, wood, trash, plastic, tins, corroded iron sheets, wood, dirty water, even faeces, colours and figures. Such art allegorises the integrationist development and shows the raison d'être of that. They used all different mediums from video to sound installations in the open spaces. Installation arts have emerged as the integrationist interdisciplinary approach where both the human aesthetic and physical perceptions of the universe, concerns about the future of the mother earth, are visibly represented. Sometimes poets also have used such visible forms of expression. Theatre is another effective medium. From this perspective Pokhara is a living installation art, a space where both natural phenomena including the sudden avalanche of the Himalayays, ancient geological gorges and land mass sliding as a result of that, lake waters receding, new eclectic approaches to the solution being debated by academics and managers, tourism industry experts, geologists, medic men and women, and antique randy people of both the metropolis and South Asia buying and selling imagoes and figurines, converge for common goal.

One important mantra of interdisciplinarity is dynamism, a unique form of kinesthesia. That is in abundance in Pokhara. I am very happy to note that all the papers being presented in this unique interdisciplinary seminar organized by Nepali academics, organisations and promoters of environments by pulling their small resources, is a big move in the right direction. I am not alluding to the experiences of the big international organisations related to the ecology of mountains and plains, forests and rivers. Such organisations have been working in bringing multiple aspects of study and disciplines together as their work models. As an academic, a teacher, I see interdisciplinarity as a dynamic subject whose relationship should be with the pedagogy. The term interdisciplinary study itself is pedagogic. The relevance of interdisciplinary study should be judged from the point of view of transferring and sharing knowledge.

Interdisciplinary study also follows the same model as other models of postality that not only question but upturn the regime of fixed relationship of epistemology with specific areas of practices that govern our lives, or have always governed them. In English departments, this subject has been most vigorously debated. By the name 'English department' and its curricula we may understand it to be comfortably situated with its own field of study, which is the 'English' literature per se, or the literature written in English. Even though the reality is that, it has opened its gates to other subjects in the humanities, as 
well as in physical and social sciences. Now days, one particular discipline can incorporate a lot from other disciplines. The debate that centre round the question of bringing the diverse experiences of disciplines and subdisciplines home in today's world focus on discussions taking place in the domains of arts and humanities, that includes literature. A great deal of attentions from people who practise various other subjects as their academic disciplines, have also enriched such studies. As the subject of interdisciplinarity is big, I resist, the temptation of drifting into its world.

In the early years of the nineties of the last century, we at the Central Department of English introduced the subject of interdisciplinarity in the curricula of English. One American professor named Julie Thompson Klein who was experimenting with interdisciplinarity in her Wayne State University in America brought some of her experiments and introduced into our system. We produced faint photocopies of the texts that etiolated as soon as we shifted to other forms of experiments. In the representative collection of interdisciplinary studies, a copy of which I recovered from my shelf, we have written these words of introduction, "This reader introduces core definitions, surveys of programme types and the history of interdisciplinary studies. It also goes beyond these items to evaluate the idea of interdisciplinarity philosophically and practically". And we have put a modicum of our optimism that the volume would "prepare the readers in the task of integrating disciplinary perspectives on any theme or topic". ${ }^{3}$ Among my favourite entries that make tremendous sense even today are, Julie T. Klein's introductory essay about the evolution in interdisciplinarity, Stanley Fish's "Being interdisciplinary is so very had to do", and Richard C. Turner's dialogic engagement with Fish "Trading tunes with Stanley Fish: Grand unification theories and the practice of literature and sciences', and M Garrett Bauman's remarkable essay "Interdisciplinary Studies for the Twenty-First Century" in which he asserts, 'the individuals must be the interdisciplinary thinkers'. Klein continued with her pioneering works in America in this area. In a book published after she left our department, I found her turning the interdisciplinarity into a cultural studies project. She finds, as I have mentioned below, the American studies benefiting tremendously from the interdisciplinarity because it incorporates both epistemology and practice from diverse disciplines. Here I would find it appropriate to quote from her book on this subject, as more than any other Western academics, Julie Klein opened new avenues of studies in the filed of interdisciplinarity. She says

The ideas of humanities, culture, and interdisciplinarity converge with particular force in the concept of "American cultural studies." The term is enjoying currency in the field of American studies, driven by changes in the definition of culture and the burgeoning field of cultural studies.... However, the study of culture in the American academy is not confined to a single field. It is a broad-based set of interests located within and across disciplines and interdisciplinary fields. Moreover, while this project requires examining changes in the way that American culture in particular is being studied, the current interdisciplinary reconfiguration of the idea of 


\section{Crossing the Border: International Journal of Interdisciplinary Studies}

culture cannot be understood without also factoring in new understand-

ings of European tradition and the global arena ... ${ }^{4}$

Europeans and Americans understood the spirit of interdisciplinarity through explorations, interventions and experiments of physical, cultural and spiritual orders, and by factoring in or out the interdisciplinary forms according their needs.

I do not want to sound as though I was indulging in the solipsistic recollection of our experiment in the nineties. But as an academic whose students have taken these studies to newer modes of studies today, it would be incomplete if I did not mention the historicity of the academia. The reason why I say this is that histories of academic departments fade round the corners, which is considered their rightful space because nobody takes up the cudgel to bring to notice them again. I want to close this historical anecdote by adding that since the time of this little experiment, all other studies went in multidisciplinary ways. The most conspicuous candidate was American Studies that we formulated fully and got approved through the University, which was a joint effort of different disciplines, and as Julie Klein puts it, it benefited most from interdisciplinary studies. Academics from geography, economics, science, sociology, women studies, and history departments came to our programmes and made full participation. That perhaps was the major thrust in this discipline that we developed in the very last years of the last century and the early years of this century at the Central Department of English. Even though the subject did not make headway due to university's unwillingness to see it grow, the graduate curricula of the English departments of Tribhuvan University and Pokhara University today show that under the able leadership and teaching of the young academics, some of the seniors among them can be said to be still on the sunny side of life, interdisciplinarity has earned its place in the academic programmes. We feel so happy to note that matter. This interdisciplinary seminar is yet another major activity organised by some of the English teachers in tandem with the academics of other disciplines.

But we should not forget that interdisciplinary studies are quietly being adopted in various academic branches of study in universities in Nepal. Sociology, anthropology, geography, chemistry, environmental sciences, population studies, tourism studies, economics, management studies, etc., all have incorporated strands of various academic disciplines in their academic structures in a number of ways. The erstwhile development studies, the present rural development studies, and the environmental and ecological studies incorporate different modes of studies related to society, nature, culture and arts. But the overall common concerns are also drawing us towards some form of shared interactions.

The ecological crisis itself is a topic that needs various modes of perception including political and economic, because today different agencies, multinational companies and even governments with interest in promoting their own trade interest can be seen creating not the solutions but crisis as models for sale. We should carefully look into the crisis models and see if we are trapped 
into those models and becoming party in the global standardisation pattern. But we have our own problems, some of which we share globally. Most important part of this process is, we should have our reasons to see if our land is turning infertile; if our forest covers are depleting or growing; if our actions are choking our rivers and cities, and if our academic disciplines are too narrowly focussed to have a comprehensive picture of these problems. Interestingly, interdisciplinarity comes in when we begin to run out of options. Our own epistemology of interdisciplinarity thus gives us the best way to get out of the catch-22 situation.

I have briefly touched upon the cultural memories that we share in $\mathrm{Ne}$ pal when we are face to face with the stark reality. Culture has come to take its place in interdisciplinary studies today. 'Cultural memory is remarkably interdisciplinary', says a preface article in a book Media and Cultural Memory. It says:

Concepts of cultural memory circulate in history, the social and political sciences, philosophy and theology, psychology, the neurosciences, and psychoanalysis, as well as in literary and media studies. Sometimes these concepts converge; at other times they seem to exclude one another; and all too often, researchers in one discipline seem to take no notice of the work done in neighbouring disciplines. ${ }^{5}$

What is the common memory that circulates among us today? We are speaking about the power of memory in this land especially in terms of its diversity. Do we have any memories related to interdisciplinarity that link us together today? My perception is that interdisciplinarity that we are seeking to evoke as a subject or as a path finder today is perhaps the most valid, and timely awareness that opens for us new avenues to work both inside the academia, and outside it in the practical life, in different areas of pragmatism as covered in the papers being presented in this seminar. But I would like to stress again, our memories are not only linked to common culture, practices, rituals and festivities or to our modus Vivendi which are diverse, but are also linked to our geological, cultural, phenomenal times and spaces. That is why Pokhara, I would say again, is both a metaphor and allegory of this kind of memory. I think, to find a way to create awareness we should all review our pedagogical practices and create some space in our curricula for interdisciplinary studies. But we should not limit interdisciplinarity as a mere academic exercise, because it is an awareness that has become an atmosphere of our common psyche. I hope the Pokhara allegory, the Pokhara locus, will answer all the questions that I have only been able to raise here this morning.

\section{NOTES}

1. Keynote speech delivered at the "The Crossing the Border Conference 2014 on Interdisciplinary Studies/Research in Climate Change," jointly organized by Crossing the Border: International Journal of Interdisciplinary Studies and Institute of Science and Technology, Tribhuvan University, Prithvi Narayan Campus, Pokhara, which was held on 13 \& 14 June 2014 in Pokhara, Nepal. 
2. Theo van Leeuwen, 'Three models of interdisciplinarity' in (Critical) Discourse Analysis Theory, methodology and interdisciplinarity, ed, Ruth Wodak and Paul Chilton (Amsterdam / Philadelphia: John Benjamins Publishing Company, 2005), p 3.

3. S.P. Lohani, R.P. Adhikari, A. Subedi, Interdisciplinary Theory and Practice, part 1. Photocopy 1995.

4. Julie Thompson Klein, Humanities, culture, and interdisciplinarity : the changing American academy (New York: State University of New York, 2005), p 3.

5. Astrid Erll and Ansgar Nunning (eds), "Preface", Media and Cultural Memory (Berlin, New York: Walter de Gruyter, 2008) p v.

\section{ABOUT THE AUTHOR}

Dr. Abhi Subedi, who has taught for over 40 years at the Central Department of English, Tribhuvan University, Nepal, has received his higher education in Nepal and Britain. He is a renowned Nepali poet, playwright, linguist, cultural scholar and critic. His best known works are his poems, plays and critical works that incorporate memories from his childhood and workplaces. He is also a columnist for several Nepali dailies such as The Kathmandu Post and Kantipur Daily, among others. He has published more than two dozens of books, both in Nepali and English (some in English translations) and is specifically praised for his contribution in promoting Nepali literature and English writing from Nepal.

Prof. Subedi is Vice-President of the Nepali Folklore Society of Nepal and member of International Association of Theatre Critics. He is the founding former President of the International Theatre Institute (ITI) UNESCO from 2000-2008 and member of International Playwright's Forum from 2000-2011. He became President (19901992) and two times General Secretary of the Linguistic Society of Nepal. He was also President of the Literary Association of Nepal.

Prof. Subedi's essays and seminar papers are published in Nepal and outside. He has attended seminars and presented papers in different countries of Asia, Europe, Africa, USA and South America. Areas covered in his presentations are literature, theatre, folklore, art and cultural studies.

Email:abhi.subedi@gmail.com 